\title{
Effect of limestone particle size on bone quality characteristics of hens at end-of-lay
}

\author{
F.H. de Witt" ${ }^{\#}$ N.P. Kuleile, H.J. van der Merwe and M.D. Fair \\ Department of Animal, Wildlife and Grassland Sciences, University of the Free State, P.O. Box 339, \\ Bloemfontein 9300, South Africa
}

\begin{abstract}
A study was conducted to determine the effect of different limestone particle sizes in layer diets on bone quality characteristics at end-of-lay hens. Calcitic limestone (360 g Ca/kg DM) that is extensively used in commercial poultry diets was obtained from a specific South African source. Limestone particles were graded as small $(<1.0 \mathrm{~mm})$, medium $(1.0-2.0 \mathrm{~mm})$ and large $(2.0-3.8 \mathrm{~mm})$ and included $(94.4 \mathrm{~g} / \mathrm{kg})$ into isoenergetic (14.3 MJ AME/kg DM) and isonitrogenous (172 g CP/kg DM) layer diets. Sixty-nine, individual caged Lohmann-Silver pullets, 17 weeks of age, were randomly allocated to the three treatments $(n=23)$ for the determination of various bone dimensional and mechanical properties at end-of-lay. At 70 weeks of age, 10 birds per treatment $(n=10)$ were randomly selected and sacrificed for the removal of tibia and humerus bones. Different limestone particle sizes had no effect on bone weight, length or diameter at 70 weeks of age. However, an increase in limestone particle size resulted in a significant increase in tibia breaking strength and -stress. These results suggested that larger particles limestone $(>1.0 \mathrm{~mm})$ have a beneficial effect on improving the mechanical properties of bone of older laying hens.
\end{abstract}

Keywords: Lohmann-Silver, bone strength, -stress, -mineralization

${ }^{\#}$ Corresponding author. E-mail: dewittfh.sci@ufs.ac.za

\section{Introduction}

The high skeletal fracture incidence (29\%) recorded by Gregory \& Wilkins (1989) illustrated that osteoporosis could result in severe welfare and economic problems in laying hens, especially towards end-oflay, during the depopulation of spent hens and during the further processing of these hens. Gregory \& Wilkins (1989) also reported that $98 \%$ of the spent hen carcasses contained broken bones by the time that they reached the end of the evisceration line.

Cheng \& Coon (1990), Guinotte \& Nys (1991) and Fleming et al. (1998a; 2003) reported an increase in bone strength, tibial radiographic densities and percentage bone ash with particulated calcium (Ca) sources. The use of particulated limestone in layer diets resulted in a decreased loss of cancellous bone and an increased medullary bone content (Fleming et al., 1998a; Rennie et al., 1997). The results of Guinotte \& Nys (1991) and Fleming et al. (1998b) suggested that the physical size of the Ca source rather than the origin of the source is responsible for the specific increase in bone strength. Fleming et al. (1998b; 2003) concluded that the provision of $\mathrm{Ca}$ in particulated form decreased the severity of some of the characteristics of osteoporosis by enhancing medullary bone formation, thereby inhibiting structural bone resorption as well as contributing directly to bone strength. Particulated Ca sources which are retained longer in the gizzard than powdered sources provide a better source of Ca for eggshell formation during nighttime. A more efficient incorporation of dietary Ca from large particulated Ca sources into eggshells has presumably a sparing effect on the need for medullary bone resorption (Fleming et al., 2003), subsequently resulting in an improvement of bone quality characteristics.

From the literature it seems that the correct particle size of Ca supplements could limit the detrimental impact on skeletal disorders and welfare issues in older laying hens (Keshavarz et al., 1993; Fleming et al., 1998a; b). However, due to confounded effects such as differences in Ca sources, particle sizes, age and genotype of birds as well as dietary Ca inclusion levels, it is impossible to make meaningful comparisons and final conclusions from these documented studies. Therefore, the ideal particle size for this specific purpose needs to be identified and better defined since much controversy still exists.

The aim of the study was to determine the effect of a specific calcitic limestone source with differing particle sizes, on bone quality characteristics of layers at end-of-lay. 


\section{Materials and Methods}

All procedures conducted during this study were approved by the Control Committee for Animal Experimentation of the University of the Free State (Animal Experiment No. 13/06). Limestone (360 g Ca/kg DM) obtained from a commercial supplier, were graded according to particle size as small $(<1.0 \mathrm{~mm})$, medium $(1.0-2.0 \mathrm{~mm})$ and large $(2.0-3.8 \mathrm{~mm})$, representing the three treatments. The experimental diet, containing 172 g crude protein/kg DM, $14.3 \mathrm{MJ}$ apparent metabolisable energy $/ \mathrm{kg} \mathrm{DM}, 51.1 \mathrm{~g}$ fat $/ \mathrm{kg} \mathrm{DM}$, $39.9 \mathrm{~g} \mathrm{Ca} / \mathrm{kg} \mathrm{DM}$ and $6.4 \mathrm{~g}$ available phosphorus/kg DM was supplied to the animals for the duration of the experimental period.

Sixty-nine (69), individually caged (1600 $\mathrm{cm}^{2} /$ bird) Lohmann-Silver pullets, 17 weeks of age (1655 $\pm 18 \mathrm{~g}$ ), were obtained from a commercial egg producer and randomly allocated to the three treatments ( $\mathrm{n}$ $=23)$. At 70 weeks of age, 10 birds per treatment $(n=10)$ were randomly selected, weighed and sacrificed by cervical dislocation before both tibias and right humerus bones were excised for the determination of various bone quality characteristics. Defleshed, full-fat bones (tibia and humerus) were weighed $(0.01 \mathrm{~g})$ while bone diameter and -length were measured with a caliper $(0.01 \mathrm{~mm})$ before they were stored at $-18{ }^{\circ} \mathrm{C}$ for analysis of bone breaking strength and bone ash content (Zhang \& Coon, 1997).

Bone breaking strength of the right tibias and humeri were determined (Fleming et al., 1998a; b) by means of a three-point destructive bending test, using an Instron tensile/compression machine that takes force readings every 0.02 seconds. The centre point of each bone was placed between two restraining bars which were set $30 \mathrm{~mm}$ apart and the crosshead probe approached the bone at $30 \mathrm{~mm} / \mathrm{min}$ until the bone was broken. Breaking strength was expressed in Newton $\left(\mathrm{N} / \mathrm{m}^{2}\right)$ and used for the calculation of bone stress (Crenshaw et al., 1981).

One hundred and fifty milliliters of hexane (98\%) were used as solvent for fat extraction of the left tibia bones, before determining dry fat-free bone weight (Al-Batshan et al., 1994). Dry fat-free tibia bones were ashed in a muffle furnace at $600{ }^{\circ} \mathrm{C}$ for $24 \mathrm{~h}$ (McCoy et al., 1996) to determine bone ash (g) which was used for the calculation of percentage tibia ash (Al-Batshan et al., 1994).

The PROC ANOVA procedures of the SAS program (SAS, 1999) were used to test for significant $(\mathrm{P}<0.05)$ differences between treatment means while Tukey's studentized range (HSD) test was used to identify the differences.

\section{Results and Discussion}

The effect of different particle sizes limestone on bone dimensional properties is presented in Table 1 . Limestone particle size had no ( $\mathrm{P}>0.05)$ effect on any of these parameters at end-of-lay. Results of the present study are in agreement with that of Keshavarz et al. (1993) who reported that neither Ca source nor

Table 1 The effect of different particle sizes limestone on bone dimensional properties of laying hens at 70 weeks of age (Mean \pm s.e.)

\begin{tabular}{|c|c|c|c|c|c|}
\hline \multirow{2}{*}{ Parameter } & \multicolumn{3}{|c|}{ Particle size (mm) } & \multicolumn{2}{|c|}{ Significance } \\
\hline & $<1.0$ & $1.0-2.0$ & $2.0-3.8$ & $\mathrm{P}^{1}$ & $\mathrm{CV}^{2}(\%)$ \\
\hline \multicolumn{6}{|l|}{ Tibia bone } \\
\hline Weight (g) & $10.3 \pm 0.4$ & $10.4 \pm 0.4$ & $10.9 \pm 0.3$ & 0.37 & 9.7 \\
\hline Length (mm) & $116.8 \pm 1.5$ & $118.9 \pm 1.1$ & $114.3 \pm 4.1$ & 0.48 & 7.1 \\
\hline Diameter (mm) & $6.4 \pm 0.0$ & $6.5 \pm 0.1$ & $6.5 \pm 0.1$ & 0.91 & 3.6 \\
\hline \multicolumn{6}{|l|}{ Humerus bone } \\
\hline Weight (g) & $3.9 \pm 0.2$ & $3.7 \pm 0.2$ & $3.8 \pm 0.2$ & 0.74 & 15.2 \\
\hline Length (mm) & $78.1 \pm 0.7$ & $78.3 \pm 0.7$ & $78.4 \pm 0.7$ & 0.93 & 2.8 \\
\hline Diameter (mm) & $6.1 \pm 0.1$ & $6.1 \pm 0.1$ & $6.2 \pm 0.1$ & 0.80 & 5.1 \\
\hline
\end{tabular}


particle size had any effect on the tibia weights of laying hens at 62 weeks of age. The report of Whitehead \& Fleming (2000) indicated that since cortical bone re-absorption is confined to endoseal surfaces any decline in structural cortical and trabecular bone components would have no influence on the external dimensions of long bones.

Results of the present study are, however, in disagreement with that of Fleming et al. (1998b) who reported that larger particles limestone increases the cancellous bone volume in the proximal tarsometatarsus due to the increased accumulation of medullary bone. Since limestone particle size did not influence $(\mathrm{P}>0.05)$ bone weight during the present study, it is suggested that medullary bone accumulation and/or depletion within the long bones of hens were constant across treatments. By using diets containing 30.0, 35.0 and $40.0 \mathrm{~g} \mathrm{Ca} / \mathrm{kg} \mathrm{DM}$, Keshavarz et al. (1993) stated that dietary Ca levels are the main determinant of bone dimensional properties, rather than particle size itself. The relatively high dietary Ca-level $(39.95 \mathrm{~g} \mathrm{Ca} / \mathrm{kg}$ DM) used during the present study could have contributed to the indistinguishable effects of larger particles limestone on bone dimensional properties, as suggested by Keshavarz et al. (1993). Therefore, differences in results between the present study and that of Fleming et al. (1998b) could possibly be ascribed to genetic differences, environmental temperature, housing and rearing conditions, lighting regime, Ca sources and nutritional factors, as well as egg output.

The effect of different particle sizes limestone on bone mechanical properties is presented in Table 2 . An increase in limestone particle size resulted in an increased tibia breaking strength $(\mathrm{P}=0.01)$ and -stress $(\mathrm{P}=0.04)$ of layers at 70 weeks of age. However, different particle sizes limestone had no $(\mathrm{P}>0.05)$ effect on tibia bone ash and humerus breaking strength and -stress. Results of the present study is in accordance with that of Miller \& Sunde (1975), Cheng \& Coon (1990) and Guinotte \& Nys (1991) who reported that larger particles limestone resulted in a higher tibia bone breaking strength than ground sources, especially during the later stages (>66 weeks of age) of production (Fleming et al., 1998b).

Table 2 The effect of different particle sizes limestone on bone breaking strength (BBS) and bone stress (BS) of laying hens at 70 weeks of age (Mean \pm s.e.)

\begin{tabular}{cccccc}
\hline \multirow{2}{*}{ Parameter } & \multicolumn{3}{c}{ Particle size $(\mathrm{mm})$} & \multicolumn{2}{c}{ Significance } \\
\cline { 2 - 6 } & $<1.0$ & $1.0-2.0$ & $2.0-3.8$ & $\mathrm{C}$ & \\
\hline Tibia bone & & & & \\
BBS $\left(\mathrm{N} / \mathrm{m}^{2}\right)$ & $276.3^{\mathrm{b}} \pm 21.1$ & $332.0^{\mathrm{ab}} \pm 26.8$ & $395.0^{\mathrm{a}} \pm 29.7$ & 0.01 & 24.5 \\
$\mathrm{BS}^{3}\left(\mathrm{~kg} / \mathrm{cm}^{2}\right)$ & $101.2^{\mathrm{b}} \pm 8.0$ & $121.2^{\mathrm{ab}} \pm 10.5$ & $143.6^{\mathrm{a}} \pm 13.5$ & 0.04 & 28.1 \\
Ash $(\%)$ & $59.9 \pm 1.2$ & $61.4 \pm 0.8$ & $61.3 \pm 0.7$ & 0.46 & \\
Humerus bone & & & & \\
BBS $^{2}\left(\mathrm{~N} / \mathrm{m}^{2}\right)$ & $236.7 \pm 21.5$ & $252.2 \pm 18.5$ & $256.5 \pm 20.9$ & 0.77 & 25.3 \\
BS $^{3}\left(\mathrm{~kg} / \mathrm{cm}^{2}\right)$ & $98.6 \pm 7.6$ & $110.7 \pm 10.0$ & $108.9 \pm 12.8$ & 0.69 & 30.8
\end{tabular}

\footnotetext{
${ }^{\mathrm{a}, \mathrm{b}}$ Parameter means \pm s.e. within rows with different superscripts differ significantly $(\mathrm{P}<0.05)$.

${ }^{1}$ Coefficient of variation; ${ }^{2}$ Bone breaking strength; ${ }^{3}$ Bone stress.
}

The improvement in bone breaking strength by using larger particles limestone (Cheng \& Coon, 1990; Guinotte \& Nys, 1991) are mainly ascribed to the increased medullary bone content and the decreased loss of cancellous bone (Rennie et al., 1997; Fleming et al., 1998b). However, contrary to these reports, Knott et al. (1995) reported that the medullary bone content has no effect on dry bone weight and bone breaking strength. Therefore, the improvement in bone breaking strength (Table 2) could probably be ascribed to the changes in morphometric characteristics of the bones, rather than the accumulation of medullary bone reserves, since bone weight (Table 1) was not affected by treatment. Humeri bones which are known to be faster depleted of medullary bone reserves are not affected by dietary treatment during the present study, suggesting that the improvement of tibia strength and stress by using larger particles limestone could not be ascribed to the accumulation of medullary bone. From the present study, it seems that an increase in 
limestone particle size $(>1.0 \mathrm{~mm})$ would improve bone breaking strength and -stress of laying hens towards end-of-lay.

\section{Conclusions}

Results from the present study indicated that an increase in limestone particle size resulted in an increased tibia breaking strength and -stress at end-of-lay. These results suggested that limestone particles $(>1.0 \mathrm{~mm})$ from this specific source would supply sufficient $\mathrm{Ca}^{2+}$ to improve bone mechanical properties at end-of-lay, thereby limiting the associated welfare issues regarding bone breakages during depopulation of spent hens.

\section{References}

Al-Batshan, H.A., Scheideler, S.E., Black, B.L., Garlich, J.D. \& Anderson, K.E., 1994. Duodenal calcium uptake, femur ash and eggshell quality decline with age and increase following molt. Poult. Sci. 73, 1590-1596.

Cheng, T.K. \& Coon, C.N., 1990. Effect of calcium source, particle size, limestone solubility in vitro and calcium intake level on layer bone status and performance. Poult. Sci. 69, 2214-2219.

Crenshaw, T.D., Peo Jr., E.R., Lewis, A.J. \& Moser, B.D., 1981. Bone strength as a trait for assessing mineralization in swine: A critical review of techniques involved. J. Anim. Sci. 53, 827-835.

Fleming, R.H., McCormack, H.A., McTeir, L. \& Whitehead, C.C., 1998a. Medullary bone and humeral breaking strength in laying hens. Res. Vet. Sci. 64, 63-67.

Fleming, R.H., McCormack, H.A. \& Whitehead, C.C., 1998b. Bone structure and strength at different ages in laying hens and effects of dietary particulated limestone, vitamin $\mathrm{K}$ and ascorbic acid. Br. Poult. Sci. 39, 434-440.

Fleming, R.H., McCormack, H.A., McTeir, L. \& Whitehead, C.C., 2003. Effects of dietary particulated limestone, vitamin $\mathrm{K}_{3}$ and fluoride and photostimulation on skeletal morphology and osteoporosis in laying hens. Br. Poult. Sci. 44, 683-689.

Gregory, N.G. \& Wilkins, L.J., 1989. Broken bones in domestic fowl: Handling and processing damage in end-of-lay battery hens. Br. Poult. Sci. 30, 555-562.

Guinotte, F. \& Nys, Y., 1991. Effects of particle size and origin of calcium sources on eggshell quality and bone mineralization in egg laying hens. Poult. Sci. 70, 583-592.

Keshavarz, K., Scott, M.L. \& Blanchard, J., 1993. The effect of solubility and particle size of calcium sources on shell quality and bone mineralization. J Appl. Poult. Res. 2, 259-267.

Knott, l., Whitehead, C.C., Fleming, R.H. \& Bailey, A.J., 1995. Biochemical changes in the collagenous matrix of osteoporotic avian bone. Biochem. J. 310, 1045-1051.

McCoy, M.A., Reilly, G.A.C. \& Kilpatrick, D.J., 1996. Density and breaking strength of bones of mortalities among caged layers. Res. Vet. Sci. 60, 185-186.

Miller, P.C. \& Sunde, M.L., 1975. The effect of various sizes oyster shell and limestone on performance of laying Leghorn pullets. Poult. Sci. 54, 1422-1433.

Rennie, J.S., Fleming, R.H., McCormack, H.A., McCorquodale, C.C. \& Whitehead, C.C., 1997. Studies on effects of nutritional factors on bone structure and osteoporosis in laying hens. Br. Poult. Sci. 38, 417-424.

SAS, 1999. SAS/STAT ${ }^{\circledR}$ User’s Guide: Statistics, Version 6.12, SAS Institute Inc., Cary, N.C., USA.

Whitehead, C.C. \& Fleming, R.H., 2000. Osteoperosis in cage layers. Poult. Sci. 79, 1033-1041.

Zhang, B. \& Coon, C.N., 1997. The relationship of calcium intake, source, size, solubility in vitro and in vivo and gizzard limestone retention in laying hens. Poult. Sci. 76, 1702-1706. 